\title{
Isolated post SARS-CoV-2 diplopia
}

\author{
Thiago Gonçalves dos Santos Martins ${ }^{1,2}$ (])
}

Received: 26 June 2020 / Accepted: 10 July 2020 / Published online: 18 July 2020

(c) Springer-Verlag GmbH Germany, part of Springer Nature 2020

Dear Sirs

In response to the article titled "Isolated post SARS-CoV-2 diplopia" published in your esteemed journal, which is a well thought off and written paper, I would like to raise a few points regarding this study. The article showed that SARS-Cov-2-related third cranial nerve palsy should be a diagnosis of exclusion but physicians should be aware of possible ocular motor dysfunction [1].

Patients with COVID-19 infection may also experience changes in eye motility along with Miller Fisher syndrome. It is a rare, acquired nerve disease that is considered to be a variant of Guillain-Barré syndrome. It is characterized by abnormal muscle coordination, paralysis of the eye muscles, and absence of the tendon reflexes [2]. The virus can cause neurological damage by neuroinflammatory or autoimmune mechanisms. The virus binds to angiotensin-converting enzyme 2 receptors, which are present in the tissue of the nervous system [3].

Another direct or indirect lesion of the virus has already been described in the abducent nerve, leading to a symptom of Abducens nerve palsy in a 32-year-old patient after an infection with SARS-CoV-2 [4].

It is important to study other possible mechanisms that explain the change in patients' extrinsic ocular motility. Other viruses that can lead to altered ocular motility have been described, such as the Chikungunya virus. This virus causes the release of cytokines that have direct and indirect neurotoxic action. Techniques of immunohistochemistry have already demonstrated that infected neurons can undergo apoptosis [5].

\section{Compliance with ethical standards}

Conflicts of interest The author declare that they have no conflict of interest.

Ethical standard statement This letter fulflled the Ethical standards.

\section{References}

1. Faucher A, Rey PA, Aguadisch E, Degos B (2020) Isolated post SARS-CoV-2 diplopia. J Neurol. https://doi.org/10.1007/s0041 $5-020-09987-x$ (published online ahead of print, 2020 Jun 12)

2. Dinkin M, Gao V, Kahan J et al (2020) COVID-19 presenting with ophthalmoparesis from cranial nerve palsy. Neurology. https://doi. org/10.1212/WNL.0000000000009700

3. Baig AM, Khaleeq A, Ali U, Syeda H (2020) Evidence of the COVID-19 virus targeting the cns: tissue distribution, host-virus interaction, and proposed neurotropic mechanisms. ACS Chem Neurosci 11:995-998

4. Falcone MM, Rong AJ, Salazar H, Redick DW, Falcone S, Cavuoto KM (2020) Acute abducens nerve palsy in a patient with the novel coronavirus disease (COVID-19). J AAPOS. https://doi. org/10.1016/j.jaapos.2020.06.001

5. Costa ALFA, Martins TGDS, Martins DGDS (2017) Third cranial nerve palsy after a chikungunya virus infection. Strabismus 25(4):172-175. https://doi.org/10.1080/09273972.2017.1391851
Thiago Gonçalves dos Santos Martins

thiagogsmartins@yahoo.com.br

1 Federal University of São Paulo, Botucatu St, 821 Vila Clementino, São Paulo 04023-062, Brazil

2 University of Coimbra, Coimbra, Portugal 